TITLE:

\title{
The effects of combining guaiacol and syringol on their pyrolysis
}

AUTHOR(S):

Asmadi, Mohd; Kawamoto, Haruo; Saka, Shiro

\section{CITATION:}

Asmadi, Mohd ...[et al]. The effects of combining guaiacol and syringol on their pyrolysis. Holzforschung 2012, 66(3): 323-330

ISSUE DATE:

2012-01

URL:

http://hdl.handle.net/2433/240641

RIGHT:

(C) by Walter de Gruyter $\bullet$ Berlin $\bullet$ Boston.; This is an open access article. 


\section{The effects of combining guaiacol and syringol on their pyrolysis}

\author{
Mohd Asmadi, Haruo Kawamoto* and Shiro Saka \\ Graduate School of Energy Science, Kyoto University, \\ Kyoto, Japan \\ * Corresponding author. \\ Graduate School of Energy Science, Kyoto University, \\ Yoshida-honmachi, Sakyo-ku, Kyoto 606-8501, Japan \\ Phone/Fax: +81-75-753-4737 \\ E-mail: kawamoto@energy.kyoto-u.ac.jp
}

\begin{abstract}
Pyrolysis of guaiacol/syringol mixtures was studied in an ampoule reactor $\left(\mathrm{N}_{2} / 600^{\circ} \mathrm{C} / 40-600 \mathrm{~s}\right)$ to understand the reactivities of the aromatic nuclei in hardwood lignins. By comparing the results with those of pure guaiacol or syringol, significant effects of their combination were observed during early stage pyrolysis: charring and gas formation were markedly suppressed. Yields for the tar fractions $(\mathrm{MeOH}-$ soluble) were increased by combination but the contents of GC/MS-detectable products with low molecular weight were dramatically decreased in these fractions, especially catecholtype compounds diminished, which are formed through the $\mathrm{O}-\mathrm{CH}_{3}$ homolysis reaction and subsequent donation of hydrogen atoms. These observations are discussed at the molecular level. Inhibition of the charring reaction, which can act as a strong hydrogen donor, would increase the probability of radical coupling reactions of the $\mathrm{O}-\mathrm{CH}_{3}$ homolysis products instead of the formation of catechol and pyrogallol and their derivatives. The latter compounds are important intermediates for gas formation, especially for CO. Based on these lines of evidence, a hypothesis is proposed according to which polyaromatization during carbonization activates the pyrolytic reactions of guaiacol and syringol.
\end{abstract}

Keywords: aromatic ring; charring; coking; hydrogen donor; lignin; mixture effect; polyaromatization; pyrolysis.

\section{Introduction}

Pyrolysis is the fundamental step in various thermochemical conversion processes for biomass resources, including gasification and fast pyrolysis for bio-oil production (Evans and Milne 1987; Scott et al. 1999; Bridgwater and Peacocke 2000; Dobele et al. 2011). Analytical pyrolysis is an effective way to study the chemical structures of complex polymers, such as lignins, humic substances, wood plastic composites, etc. (Shadkami and Helleur 2010; Windt et al. 2011). For better understanding of these conversions and analytical methods, lignin pyrolysis has been studied based on isolated lignins (Martin et al. 1979; Obst 1983; Evans et al. 1986; Saiz-Jimenez and De Leeuw 1986; Faix et al. 1987; Genuit et al. 1987; Meier and Faix 1992; Greenwood et al. 2002; Hosoya et al. 2007, 2008a,b; Nakamura et al. 2008) and model compounds (Domburg et al. 1974; Brežný et al. 1983; Saiz-Jimenez and De Leeuw 1986; Kawamoto et al. 2006, 2007, 2008a,b; Kawamoto and Saka 2007; Nakamura et al. 2007, 2008; Watanabe et al. 2009). Hardwood lignins are known to include both the syringyl (3,5-dimethoxy-4hydroxyphenyl)-type (shortly $S$ ) and the guaiacyl (4-hydroxy3-methoxyphenyl)-type aromatic rings (shortly G), whereas softwood lignins contain mainly the G-type units. These differences influence the pyrolytic reactivity of hardwoods and softwoods (Di Blasi et al. 2001a,b; Grønli et al. 2002; Asmadi et al. 2010). The temperatures at which major devolatilization is observed are reported to be slightly lower in hardwood lignins (Gardner et al. 1985; Faix et al. 1988; Li et al. 2002; Liu et al. 2008). Extensive studies with isolated lignins and model dimers (see citations above) were interpreted that the ether linkages between the propane side chains and aromatic rings are cleaved in a temperature range around $350^{\circ} \mathrm{C}$ splitting to form G- and S-type degradation products with double bond side chains at the $p$-position to the phenolic hydroxyl groups as the major volatile products.

After devolatilization, further pyrolysis reactions take place in both the gas and solid/liquid phases. Solid/liquid phase pyrolysis is not well known, but model compound studies describe well the gas phase reactions. Guaiacols with double bond side chains easily polymerize into solid/ liquid products (Nakamura et al. 2007; Hosoya et al. 2008b) and the side chain network is then cracked into guaiacol and its derivatives with saturated side chains (Hosoya et al. 2008b).

With increasing pyrolysis temperature, methoxy groups of the aromatic nuclei become reactive at around $400-450^{\circ} \mathrm{C}$ (Vuori and Bredenberg 1985, 1987; Vuori 1986; Dorrestijn and Mulder 1999; Asmadi et al. 2011a). Homolytic cleavage of the $\mathrm{O}-\mathrm{CH}_{3}$ bond is an important reaction (Vuori and Bredenberg 1985, 1987; Vuori 1986; Afifi et al. 1989; Dorrestijn and Mulder 1999; Hosoya et al. 2008b, 2009; Asmadi et al. 2011a). Hydrogen-donation to the resulting phenoxy and methyl radicals produces catechol and methane, respectively, in the case of guaiacol. In a radical-rich environment, a radical-induced rearrangement (ipso-substitution) occurs, starting from the phenoxy radicals formed by H-abstraction from the hydroxyl groups of G and S units (Dorrestijn and Mulder 1999; Hosoya et al. 2009; Asmadi et al. 2011a). Methyl phenols - such as $o$-cresol and 2,6-xylenol - are formed through this rearrangement pathway. 
Coke (char), which is defined as a carbonaceous substance formed via volatile products, is also a product of this rearrangement pathway (Hosoya et al. 2009; Asmadi et al. 2011a,b). Hosoya et al. (2009) found that the methoxy group is an important structural element in coke formation and proposed $o$-quinonemethide as a key intermediate in coke formation, which arises in the course of the rearrangement pathway. Demethoxylation was also suggested to occur through decarbonylation of the aldehyde derivatives formed in the rearrangement pathway (Schlosberg et al. 1983; Vuori 1986; Vuori and Bredenberg 1987; Afifi et al. 1989; Dorrestijn and Mulder 1999; Hosoya et al. 2008b; Asmadi et al. 2011a,b). Through these reactions, $\mathrm{G}$ and $\mathrm{S}$ units are converted into catechols/pyrogallols and methane via the homolysis pathway and cresols and xylenols, phenol and coke (char) via the rearrangement pathway (Masuku 1991; Dorrestijn and Mulder 1999; Vane and Abbott 1999; Hosoya et al. 2009; Asmadi et al. 2011a,b).

At higher temperatures $>550^{\circ} \mathrm{C}$ to $600^{\circ} \mathrm{C}$, gasification of these intermediates becomes effective (Asmadi et al. 2011a,b). The reactivity of catechols and pyrogallols is higher than that of cresols and xylenols. The former give mainly $\mathrm{CO}$, whereas the latter result in $\mathrm{H}_{2}$ and $\mathrm{CH}_{4}$ along with the demethylation products.

Asmadi et al. (2011a) compared the pyrolytic reactivities of guaiacol and syringol as model aromatic nuclei for lignin in an ampoule reactor $\left(\mathrm{N}_{2} / 600^{\circ} \mathrm{C} / 40-600 \mathrm{~s}\right)$. The authors found that syringol has much higher reactivity in charring and gas formation and this was explained by the double opportunity for $o$-quinonemethide formation due to the presence of a second methoxy group. Efficient gas formation from syringol is due to the greater reactivities of the syringol-derived catechols and pyrogallols (Asmadi et al. 2011b). Accordingly, the $\mathrm{S}$ units in lignin are more reactive than the $\mathrm{G}$ units during pyrolysis. In this paper, pyrolysis of guaiacol and syringol mixtures was studied in an ampoule reactor under $\mathrm{N}_{2}$ at $600^{\circ} \mathrm{C}$ to improve the understanding of the aromatic ring reactivity during pyrolysis of hardwood lignins.

\section{Materials and methods}

Guaiacol and syringol were purchased from Nacalai Tesque Inc. (Kyoto, Japan) as guaranteed grades. A guaiacol/syringol mixture $(5 / 5 \mathrm{mg}$ or $3 / 7 \mathrm{mg})$ was placed at the bottom of a Pyrex glass ampoule (internal diameter: $8.0 \mathrm{~mm}$; length: $120 \mathrm{~mm}$ : wall thickness: $1.0 \mathrm{~mm}$ ). The glass ampoule was closed after exchanging the internal air with $\mathrm{N}_{2}$. The ampoule was heated for 40-600 s in an upright orientation by inserting the ampoule through a small hole in the top of a muffle furnace preheated at $600^{\circ} \mathrm{C}$. After pyrolysis, the ampoule was immediately cooled by flowing air for $1 \mathrm{~min}$ and opened in a gas collecting apparatus, attached to the ampoule according to a previously reported method (Hosoya et al. 2008a). The non-condensable gases were analyzed by GC, as described below. The ampoule was then extracted with $\mathrm{MeOH}(2 \times 1.0 \mathrm{ml})$ to obtain $\mathrm{MeOH}$-soluble and insoluble (char/coke) fractions. The latter fraction, stuck to the ampoule wall, was dried in an oven $\left(105^{\circ} \mathrm{C}\right)$ for $24 \mathrm{~h}$, and the coke yield was determined from the weight difference of the glassware after incineration of the coke in air at $600^{\circ} \mathrm{C}$ for $2 \mathrm{~h}$. The $\mathrm{MeOH}$-soluble tar yield was obtained by subtracting the guaiacol/syringol recovery from the yield of the $\mathrm{MeOH}$-soluble fraction, which was obtained from the weight reduction in the reactor after $\mathrm{MeOH}$ extraction.

A guaiacol/syringol mixture $(5 / 5 \mathrm{mg})$ was also pyrolyzed in the presence of guaiacol coke. Guaiacol $(10 \mathrm{mg})$ was pyrolyzed first in $\mathrm{N}_{2}$ at $600^{\circ} \mathrm{C}$ for $80 \mathrm{~s}$ in a similar way, and the resulting ampoule was opened and washed with $\mathrm{MeOH}(2 \times 1.0 \mathrm{ml})$ and then with water. After drying, the ampoule including coke fraction in an oven $\left(105^{\circ} \mathrm{C}\right)$ for $24 \mathrm{~h}$, a guaiacol/syringol mixture $(5 / 5 \mathrm{mg})$ was placed at the bottom of the ampoule. The ampoule was closed after exchanging the inside air with $\mathrm{N}_{2}$. The other procedures were similar to those described above.

Non-condensable gases were determined with a Micro GC, with a Varian CP-4900 instrument under the following conditions. Channel 1: column MS5A $10 \mathrm{~m}$; carrier gas: $\mathrm{Ar}$; column temperature: $100^{\circ} \mathrm{C}$; column pressure: $170 \mathrm{kPa}$; thermal conductivity detector (TCD); retention times (s): $\mathrm{H}_{2}$ (26.4), $\mathrm{N}_{2}$ (45.7), $\mathrm{O}_{2}$ (35.4), $\mathrm{CH}_{4}$ (60.6), and CO (86.9). Channel 2: column PoraPLOT Q $10 \mathrm{~m}$; carrier gas: He; column temperature: $80^{\circ} \mathrm{C}$ : column pressure: $190 \mathrm{kPa}$; TCD detector; retention time (s): $\mathrm{CO}_{2}(19.9)$.

Low molecular weight (MW) products in the $\mathrm{MeOH}$-soluble fractions were determined by GC-MS analysis, which was carried out on a Hitachi G-7000 GC instrument and a Hitachi M9000 mass spectrometer under the following conditions. Column: Shimadzu CBP-M25-O25 (25 m, $0.25 \mathrm{~mm}$ diameter); injector temperature: $250^{\circ} \mathrm{C}$; column temperature: $40^{\circ} \mathrm{C}(1 \mathrm{~min}), 40-300^{\circ} \mathrm{C}(1-53 \mathrm{~min})$, $300^{\circ} \mathrm{C}$ (53-60 min); carrier gas: He; flow rate: $1.5 \mathrm{ml} \mathrm{min}^{-1}$; emission current: $15 \mu \mathrm{A}$; ionization time: $100 \mathrm{~ms}$. Identification of products was conducted by comparing their retention times and mass fragmentation patterns with those of standard compounds, according to our previous studies (Hosoya et al. 2007, 2008b; Asmadi et al. 2010). Quantification was carried out based on the relative peak areas against $p$-dibromobenzene as an internal standard by means of the response factors obtained for these authentic compounds.

All experiments were repeated several times and product yields were similar across all sets of experiments, although the data presented in this section were not analyzed statistically.

\section{Results and discussion}

\section{Tar, gas, and coke/char formation}

The guaiacol and syringol recoveries and the product yields from pyrolysis of a $\mathrm{G} / \mathrm{S}$ mixture $(1: 1 \mathrm{w} / \mathrm{w})$ in an ampoule reactor under $\mathrm{N}_{2}$ at $600^{\circ} \mathrm{C}$ for $40-600 \mathrm{~s}$ are summarized in Table 1. The G/S mixture $(3: 7 \mathrm{w} / \mathrm{w})$ gave similar mixing effects, and hence only data with the mixture $(1: 1, \mathrm{w} / \mathrm{w})$ are presented. Gas yield was determined as the sum of the yields of $\mathrm{H}_{2}, \mathrm{CO}$, $\mathrm{CH}_{4}$, and $\mathrm{CO}_{2}$, and tar yield is shown as wt $\%$ of the $\mathrm{MeOH}-$ soluble fraction after subtraction of the amounts of recovered guaiacol and syringol. The values in parentheses are the expected yields based on the pyrolysis data of pure guaiacol and syringol where no interaction occurs during pyrolysis.

The G/S recoveries at $40 \mathrm{~s}$ were lower than expected, thus both guaiacol and syringol degradation is enhanced in the mixture. A yield ratio, defined as "experimental yield/ expected yield" helps quantifying the effects. Time-course changes of the yield ratios are illustrated in Figure 1a. Coke and gas yields were markedly reduced from the expected yields during early stages of pyrolysis, especially around $40 \mathrm{~s}$. 
Table 1 Influences of combining guaiacol/syringol (1:1, w/w) on guaiacol/syringol recovery and yields of coke, tar, and gaseous products.

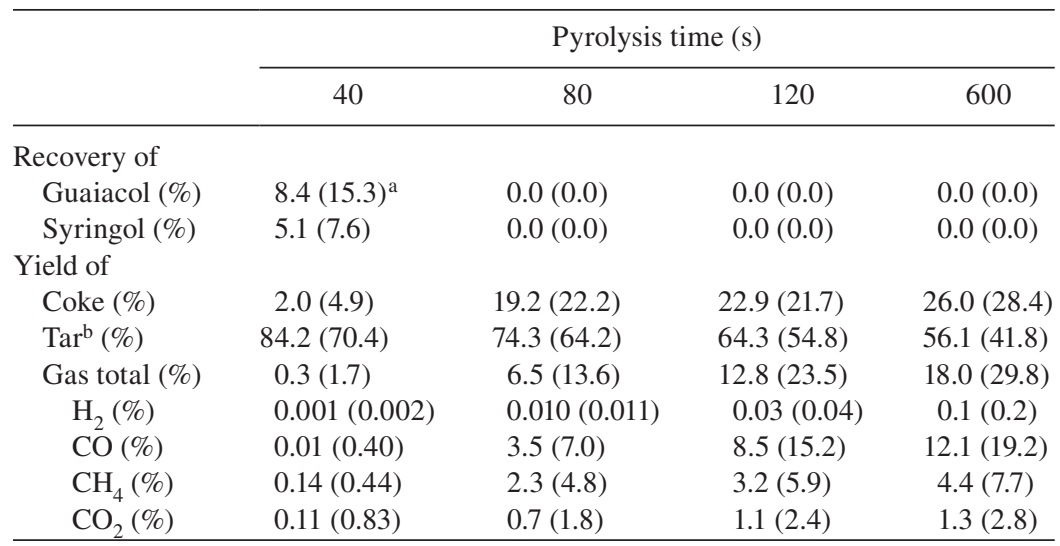

${ }^{a}$ Values in parentheses show the expected value obtained from the data of individual pyrolysis of pure guaiacol and syringol.

${ }^{\mathrm{b}}$ Excluding the starting compound.

In contrast, tar yield increased and this tendency was maintained until the pyrolysis time of $600 \mathrm{~s}$. With increasing pyrolysis time, the yield ratios of coke increased and at 120 and $600 \mathrm{~s}$ approached the expected yields. The same trend was observed for gas yield but the yield ratio leveled off at around 0.5-0.6. Accordingly, strong effects are visible in early stages of pyrolysis in a G/S mixture, which stabilize the tar fraction towards coking and gasification.

Figure $1 \mathrm{~b}$ shows the time-course changes in the yield ratios of gaseous components $\left(\mathrm{H}_{2}, \mathrm{CO}, \mathrm{CH}_{4}\right.$, and $\left.\mathrm{CO}_{2}\right)$. Their yield ratios increased until the pyrolysis time of $120 \mathrm{~s}$ and remained essentially unchanged. The CO formation was very low at $40 \mathrm{~s}$ (expected yield: $0.4 \%$ ).

\section{Tar composition}

Various low MW products were determined by GC/MS of the $\mathrm{MeOH}$-soluble fractions, including catechols and pyrogallols, cresols and xylenols and phenol. At pyrolysis times longer than $120 \mathrm{~s}$, polyaromatic hydrocarbons (PAHs) such as naphthalene and its methylated derivatives, biphenyl, anthracene, and phenanthrene were detected. These were the same compounds observed during pyrolysis of pure guaiacol or syringol (Asmadi et al. 2011a), except for the signals in the dimer region of total ion chromatograms (data not shown). Some mixed coupling products of guaiacol, syringol, and their decomposition products may be formed during the pyrolysis of the mixture.

Yields of the low MW products determined by GC/MS are presented in Figure 1c, compared with expected yields. The expected yield at $40 \mathrm{~s}$ was $4.4 \%$ but the experimental yield was only $0.1 \%$, even though the tar yield increased by $20 \%$ (a yield ratio of 1.2 at $40 \mathrm{~s}$, Figure 1a) in the pyrolysis of the mixture. Accordingly, at $40 \mathrm{~s}$, the tar became rich in larger MW products. At longer pyrolysis times than $80 \mathrm{~s}$, the gaps between expected and experimental yields were similar to that at $40 \mathrm{~s}$. Also these results indicate strong effects in the early stage of pyrolysis of G/S mixtures.
Figure 2 shows the formation and decomposition behaviors of some major low MW products, which are grouped into two types depending on the formation pathways, that is, $\mathrm{O}-\mathrm{CH}_{3}$ bond homolysis and $\mathrm{OCH}_{3}$ rearrangement (Asmadi et al. 2011a). Pyrocatechol, 3-methoxycatechol, and pyrogallol were observed only in the early pyrolysis stage. Reportedly, these compounds are converted effectively into gaseous products, mainly $\mathrm{CO}$, at temperatures above $550-600^{\circ} \mathrm{C}$ (Asmadi et al. 2011b). Formation of these $\mathrm{O}-\mathrm{CH}_{3}$ homolysis products, apart from pyrogallol, was strongly inhibited in G/S mixture, which led to diminished yields of gaseous products, especially that of $\mathrm{CO}$.

Ortho-cresol, 2,6-xylenol, and phenol were also formed in the first $120 \mathrm{~s}$. The former two compounds are the $\mathrm{OCH}_{3}$ rearrangement products from guaiacol and syringol, respectively (Masuku 1991; Dorrestijn and Mulder 1999; Vane and Abbott 1999; Hosoya et al. 2009; Asmadi et al. 2011a,b). Phenol is formed through demethoxylation and demethylation reactions (Afifi et al. 1989; Dorrestijn and Mulder 1999; Hosoya et al. 2009; Asmadi et al. 2011a,b). These compounds were comparatively stable. In our previous paper (Asmadi et al. 2011b), formation of $\mathrm{H}_{2}$ and $\mathrm{CH}_{4}$ along with coke and demethylation products were found to be the major reactions occurring between 120 and $600 \mathrm{~s}$. The formation of these products was not significantly changed in G/S mixtures.

\section{Mixing effects}

The homolytic cleavage of $\mathrm{O}-\mathrm{CH}_{3}$ bonds can occur by several pathways, as illustrated in Figure $3 \mathrm{a}$ for a $\mathrm{G}$ unit (Dorrestijn and Mulder 1999; Hosoya et al. 2009; Asmadi et al. 2011a). Similar pathways are involved in syringol pyrolysis (Masuku 1991; Vane and Abbott 1999; Asmadi et al. 2011a). $\mathrm{H}$-abstraction and H-donation play important roles in both pathways. Catechol and methyl radicals formed through the homolysis reaction (a) are stabilized into pyrocatechol (3) and methane, respectively, when two H-donors can give hydrogens 

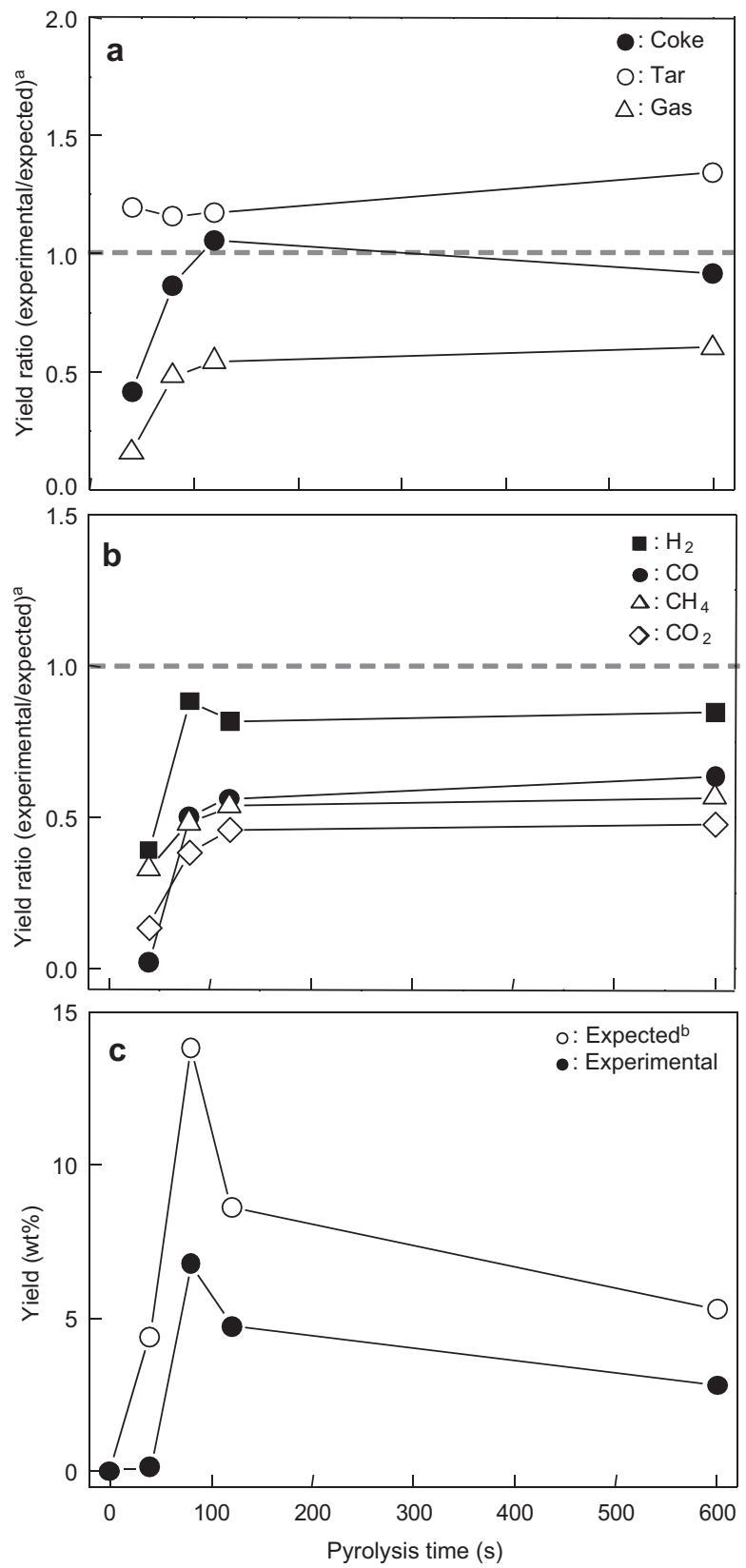

Figure 1 Influences of combining guaiacol/syringol $(1: 1, \mathrm{w} / \mathrm{w})$ on coke, tar, and gas yields (a), yields of gaseous products (b), and GC/MS-detectable tar yields (c). Pyrolysis conditions: $\left(\mathrm{N}_{2} / 600^{\circ} \mathrm{C} /\right.$ 40-600 s). ${ }^{\text {a }}$ Yield ratio=experimental yield/expected yield. ${ }^{b}$ Expected yields were obtained from the data for individual pyrolysis of pure guaiacol and syringol by assuming that no interaction occurs during pyrolysis of their mixture.

to these radicals (reactions $b$ and c). Otherwise, these radicals would be consumed by radical coupling reaction.

Other pathways (reactions d-o) in Figure 3a are via radicalinduced rearrangement (Dorrestijn and Mulder 1999; Hosoya et al. 2009; Asmadi et al. 2011a). Phenoxy radical 4, which is formed by $\mathrm{H}$-abstraction from the phenolic hydroxyl group of guaiacol, is rearranged into a benzyloxy radical 7

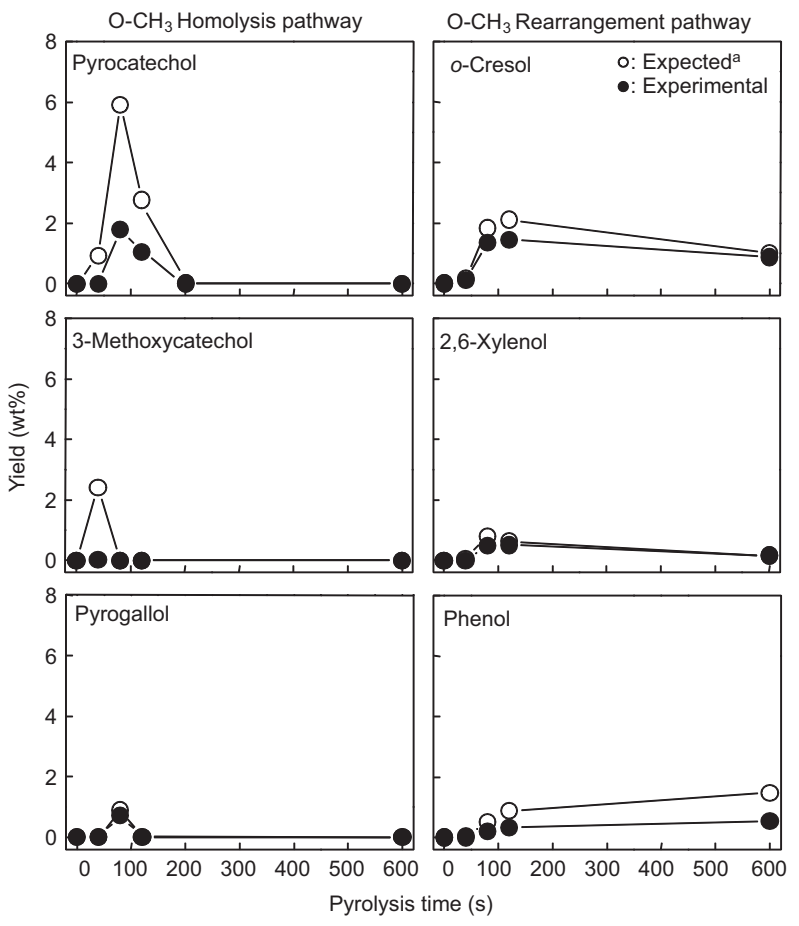

Figure 2 Influences of combining guaiacol/syringol $(1: 1, w / w)$ on yields of some GC/MS-detectable tar components formed through $\mathrm{O}-\mathrm{CH}_{3}$ homolysis and $\mathrm{OCH}_{3}$ rearrangement pathways. Pyrolysis conditions: $\mathrm{N}_{2} / 600^{\circ} \mathrm{C} / 40-600$ s. $\left(\mathrm{N}_{2} / 600^{\circ} \mathrm{C} / 40-600\right.$ s). ${ }^{a}$ Expected yields were obtained from the data of individual pyrolysis of pure guaiacol or syringol by assuming that no interaction occurs during pyrolysis of their mixture.

(ipso-substitution) (Dorrestijn and Mulder 1999; Hosoya et al. 2009; Asmadi et al. 2011a). Intermediate 7 may lead to the formation of $o$-quinonemethide 9 (Vuori 1986; Vuori and Bredenberg 1987; Afifi et al. 1989; Dorrestijn and Mulder 1999; Hosoya et al. 2009; Asmadi et al. 2011a), which is further converted into $o$-cresol (reaction j) (Dorrestijn and Mulder 1999; Hosoya et al. 2009; Asmadi et al. 2011a) and coke (reaction k) (Hosoya et al. 2009). Another pathway (reactions 1-o) forms phenol via decarbonylation (Vuori 1986; Vuori and Bredenberg 1987; Afifi et al. 1989; Dorrestijn and Mulder 1999; Hosoya et al. 2009; Asmadi et al. 2011a).

These pathways would be influenced by the concentrations of H-acceptor (radical) and H-donor, and Table 2 summarizes their theoretical amount needed for formation of pyrocatechol $/ \mathrm{CH}_{4}, o$-quinonemethide, $o$-cresol, and phenol from guaiacol. For pyrocatechol/ $\mathrm{CH}_{4}$ formation, only $\mathrm{H}$-donor is required, because catechol and methyl radicals are supplied by unimolecular decomposition of guaiacol (via $\mathrm{O}-\mathrm{CH}_{3}$ bond homolysis). On the contrary, formation of other products, which are formed through the $\mathrm{OCH}_{3}$ rearrangement pathway starting from the guaiacol radical, needs both an $\mathrm{H}$-acceptor and an $\mathrm{H}$-donor.

The mixing effects observed in the present study are explainable in terms of the $\mathrm{H}$-acceptor/H-donor theory. The yields of pyrocatechol, 3-methoxycatechol, and methane, all 
a

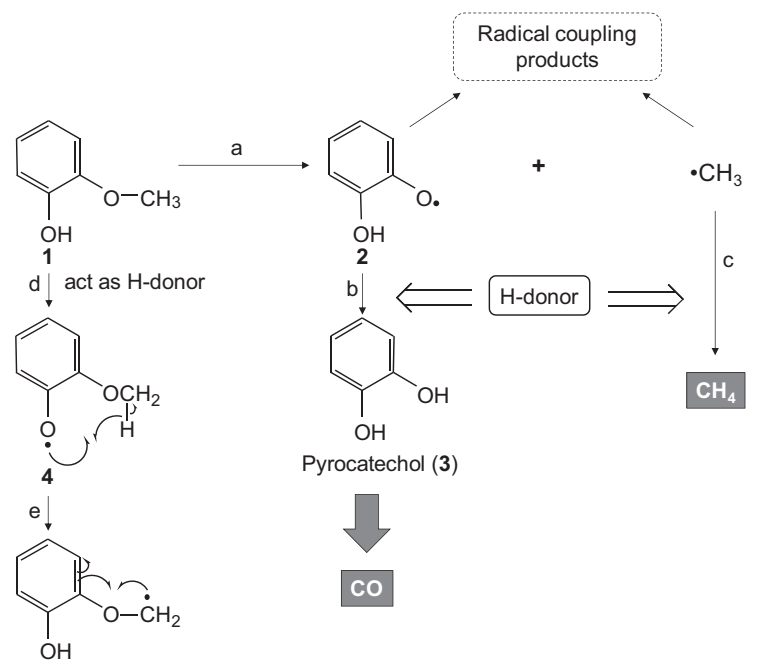<smiles>Oc1ccc(O)c(C2(O)CO2)c1</smiles><smiles>O=Cc1ccccc1OCC(=O)c1ccccc1O</smiles>

$\mathrm{h} \mid \mathrm{H}$-donor<smiles>c1ccc2c(c1)OCCOCO2</smiles>
${ }_{8}^{0},-\mathrm{O}-\mathrm{H}$<smiles>Oc1ccccc1</smiles>

Demethoxylation product (14)<smiles>O=C1CCCC1</smiles><smiles>C=C1C=CC(C)=C(C=Cc2ccccc2)C1=O</smiles>

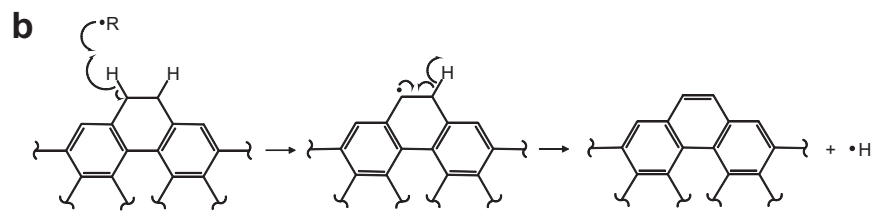

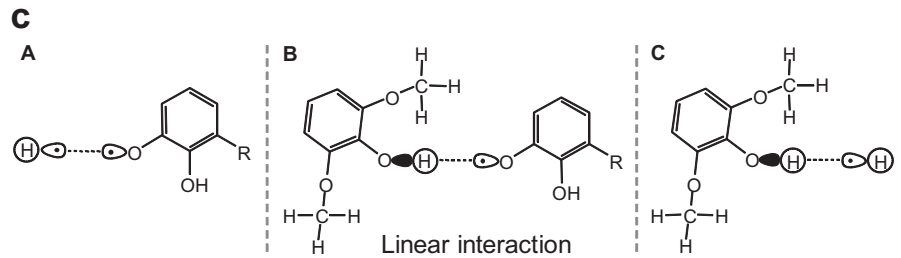

Figure 3 Thermal decomposition pathways of guaiacol focusing on the role of H-donor (a), polyaromatization in coke, and PAH formation acting as $\mathrm{H}$-donor (b), and linear transition states in $\mathrm{H}$-abstraction and $\mathrm{H}$-donation reactions (c). 
Table $2 \mathrm{H}$-acceptor and $\mathrm{H}$-donor requirements for pyrolytic formation of pyrocatechol/ $/ \mathrm{CH}_{4}, o$-quinonemethide, $o$-cresol, and phenol from guaiacol.

\begin{tabular}{lcc}
\hline \multicolumn{1}{c}{ Pyrolysis products } & H-acceptor (radical) & H-donor \\
\hline O-CH $\mathrm{CH}_{3}$ homolysis product & & \\
${\mathrm{Pyrocatechol} \mathrm{and} \mathrm{CH}_{4}}_{\mathrm{OCH}_{3} \text { rearrangement product }}$ & 0 & 2 \\
$o$-quinonemethide & 1 & 1 \\
$o$-Cresol & 1 & 3 \\
Phenol & 3 & 1 \\
\hline
\end{tabular}

Number of $\mathrm{H}$-acceptors and $\mathrm{H}$-donors for pyrolytic formation of $1 \mathrm{~mol}$ of pyrocatechol and $\mathrm{CH}_{4}, o$-quinonemethide, $o$-cresol, and phenol from guaiacol.

of which appeared with low yields at $40 \mathrm{~s}$, indicate that not enough $\mathrm{H}$-donor is available to stabilize their phenoxy and methyl radicals. These radicals may rather condense via radical coupling reactions. Judged from the increasing tar yields and suppressed CO formation, these coupling products may be stabilized for gasification, although the stabilization mechanism is currently unknown. Lower H-donor concentration is also consistent with the reduction of the $\mathrm{G} / \mathrm{S}$ recoveries.

Polyaromatization during coking and $\mathrm{PAH}$ formation would produce $\mathrm{H}$, which acts as a good $\mathrm{H}$-donor (Figure $3 \mathrm{~b}$ ). The hydrogen radical can also act as an $\mathrm{H}$-acceptor, which leads to $\mathrm{H}_{2}$.

Figure $3 \mathrm{c}$ illustrates the expected transition states for some $\mathrm{H}$-donation and $\mathrm{H}$-abstraction reactions. Stereoelectronic effects are known to be an important factor on the reactivity of H-donation to the radical (Parsons 2000) as all intermediates are striving for a linear transition state, which maximizes the interaction of the radical orbital and the vacant $\sigma^{*}$ orbital of the bond, which is going to be cleaved. In the case of B (syringyl unit), steric hindrance originating from the two methoxy groups may prevent such linear interaction. In contrast, $\mathrm{H}$-donation by the small $\mathrm{H}$ (case $\mathrm{A}$ ) would be more effective. Accordingly, low H-donor conditions in the pyrolysis of the G/S mixture may arise from the inhibited coking observed between 40 and $80 \mathrm{~s}$ (Figure 1a). However, the inhibition mechanism is not yet known. The hydrogen radical is also suggested to be a better $\mathrm{H}$-acceptor than catechol and methyl radicals for the same steric reason (case B vs. C).

To confirm this hypothesis, a G/S mixture (1:1, w/w) was pyrolyzed in the presence of guaiacol coke which was prepared by pyrolysis of guaiacol under similar conditions with 80 s pyrolysis time and subsequent tar extraction and drying. The results are presented in Table 3. Yields of the $\mathrm{O}-\mathrm{CH}_{3}$ bond homolysis products in early stage pyrolysis increased up to around the levels of the expected yields, including 3-methoxycatechol $(3.6 \%, 40 \mathrm{~s})$. Along with the increase in the recoveries of the $\mathrm{O}-\mathrm{CH}_{3}$ bond homolysis products, gas yields also increased up to around the expected yields. The recoveries of guaiacol and syringol, at $40 \mathrm{~s}$, especially guaiacol, also improved, and the guaiacol recovery (20.8\%) was higher than the expected recovery $(15.3 \%)$ in Table 1 . Based
Table 3 Yields of coke, gas, tar, and tar components in pyrolysis of a guaiacol/syringol mixture $(1: 1, w / w)$ in the presence of guaiacol coke.

\begin{tabular}{|c|c|c|c|c|}
\hline \multirow{2}{*}{$\begin{array}{c}\text { Products } \\
\text { (Reaction pathway) }\end{array}$} & \multicolumn{4}{|c|}{ Pyrolysis time (s) } \\
\hline & 40 & 80 & 120 & 600 \\
\hline \multicolumn{5}{|l|}{ Recovery of } \\
\hline Guaiacol (\%) & 20.8 & 0.0 & 0.0 & 0.0 \\
\hline Syringol (\%) & 5.5 & 0.0 & 0.0 & 0.0 \\
\hline \multicolumn{5}{|l|}{ Yield of } \\
\hline Coke $(\%)$ & 14.2 & 25.6 & 26.2 & 28.9 \\
\hline Gas total $(\%)$ & 1.4 & 14.9 & 19.2 & 32.1 \\
\hline $\mathrm{H}_{2}(\%)$ & 0.003 & 0.03 & 0.06 & 0.32 \\
\hline $\mathrm{CO}(\%)$ & 0.7 & 8.7 & 13.0 & 21.5 \\
\hline $\mathrm{CH}_{4}(\%)$ & 0.5 & 4.8 & 4.7 & 8.1 \\
\hline $\mathrm{CO}_{2}(\%)$ & 0.11 & 1.3 & 1.5 & 2.3 \\
\hline $\operatorname{Tar}(\%)$ & 58.9 & 59.5 & 54.6 & 39.0 \\
\hline \multicolumn{5}{|l|}{$\mathrm{O}-\mathrm{CH}_{3}$ homolysis } \\
\hline Pyrocatechol (\%) & 0.0 & 5.2 & 4.7 & 0.0 \\
\hline 3-Methoxycatechol (\%) & 3.6 & 0.0 & 0.0 & 0.0 \\
\hline Pyrogallol (\%) & 0.00 & 2.0 & 0.0 & 0.0 \\
\hline \multicolumn{5}{|l|}{$\mathrm{OCH}_{3}$ rearrangement } \\
\hline$o$-Cresol (\%) & 2.0 & 3.8 & 3.2 & 0.3 \\
\hline 2,6-Xylenol (\%) & 0.1 & 1.5 & 1.1 & 0.1 \\
\hline Phenol (\%) & 0.3 & 0.6 & 0.7 & 0.3 \\
\hline
\end{tabular}

Conditions of coke production: $\mathrm{N}_{2} / 600^{\circ} \mathrm{C} / 80 \mathrm{~s}$. Pyrolysis conditions: of $\mathrm{N}_{2} / 600^{\circ} \mathrm{C} / 40-600 \mathrm{~s}$.

on the discussion on Figure 3c, less hindered hydroxyl groups in guaiacol are expected to be a better $\mathrm{H}$-donor than those of syringol, and hence radical species are able to abstract hydrogen more selectively from guaiacol in the case of pyrolysis of a G/S mixture. In the presence of guaiacol coke, a better H-donor (probably H) formed from coke tends to add hydrogen to radical species, which elevates the guaiacol yield.

Interestingly, coke yield at $40 \mathrm{~s}$ increased drastically from 2.0 to $14.2 \%$, whereas tar yield at $40 \mathrm{~s}$ was reduced from 84.2 to $58.9 \%$. Thus, coking reaction was accelerated in the presence of the guaiacol coke. The yields of other $\mathrm{OCH}_{3}$ rearrangement products are also partly elevated at $40 \mathrm{~s}$ : $O$-cresol (ca. 0.1\%), 2,6-xylenol (0-2\%), and phenol (0.1-0.3\%). Accordingly, the $\mathrm{OCH}_{3}$ rearrangement pathways are activated in the presence of $\mathrm{G}$ coke. Effective $\mathrm{H}$-donation to a benzyloxy radical 7 to form a benzyl alcohol 8 (Figure 3a) in the presence of $\mathrm{G}$ coke may promote the following reactions via o-quinonemethide 9. Under less effective $\mathrm{H}$-donor conditions, the benzyloxy radical 7 may couple with other radicals to form condensates.

\section{Conclusions}

Significant effects were observed in pyrolysis of guaiacol/ syringol mixtures in an ampoule reactor under $\mathrm{N}_{2}$ at $600^{\circ} \mathrm{C}$. Coke and gas yields were markedly suppressed during early stages of pyrolysis, whereas tar yield was elevated. Formation of low MW products in the tar fraction, especially 
pyrocatechol and 3-methoxycatechol, was almost completely inhibited. These results can be explained by low H-donor availability during early stages of pyrolysis, which may have originated from the inhibited coke formation. Hydrogen radical formed during coking and PAH formation was considered to be a better H-donor. This is confirmed by the results of the experiments in the presence of guaiacol coke. Based on these lines of evidence, a hypothesis is proposed that polyaromatization during coke formation activates the pyrolytic reactions of guaiacol/syringol.

\section{Acknowledgments}

This work was supported by Grant-in-Aid for Scientific Research (B) (2) (No. 20380103, 2008.4-2012.3) and Kyoto University Global COE program of "Energy Science in the Age of Global Warming".

\section{References}

Afifi, A.I., Hindermann, J.P., Chornet, E., Overend, R.P. (1989) The cleavage of the aryl-O- $\mathrm{CH}_{3}$ bond using anisole as a model compound. Fuel 68:498-504.

Asmadi, M., Kawamoto, H., Saka, S. (2010) Pyrolysis reactions of Japanese cedar and Japanese beech woods in a closed ampoule reactor. J. Wood Sci. 56:319-330.

Asmadi, M., Kawamoto, H., Saka, S. (2011a) Thermal reactions of guaiacol and syringol as lignin model aromatic nuclei. J. Anal. Appl. Pyrol. 92:88-98.

Asmadi, M., Kawamoto, H., Saka, S. (2011b) Thermal reactivities of catechols/pyrogallols and cresols/xylenols as lignin pyrolysis intermediates. J. Anal. Appl. Pyrol. 92:76-87.

Brežný, R., Mihálov, V., Kováčik, V. (1983) Low temperature thermolysis of lignins - I. Reactions of $\beta-O-4$ model compounds. Holzforschung 37:199-204.

Bridgwater, A.V., Peacocke, G.V.C. (2000) Fast pyrolysis processes for biomass. Renew. Sust. Energ. Rev. 4:1-73.

Di Blasi, C., Branca, C., Santoro, A., Perez Bermdez, R.A. (2001a) Weight loss dynamics of wood chips under fast radiative heating. J. Anal. Appl. Pyrol. 57:77-90.

Di Blasi, C., Branca, C., Santoro, A., Gonzales Hernandez, E. (2001b) Pyrolytic behavior and products of some wood varieties. Comb. Flame 124:165-177.

Dobele, G., Dizhbite, T., Ponomarenko, J., Urbanovich, I., Kreicberga, J., Kampars, V. (2011) Isolation and characterization of the phenolic fractions of wood pyrolytic oil. Holzforschung 65:503-510.

Domburg, G.E., Rossinskaya, G., Sergeeva, V. (1974) Study of thermal stability of $\beta$-ether bonds in lignin and its models. In: Proceedings of the Fourth International Conference on Thermogravimetric Analysis, Akademia kaido, Budapest, Vol. 2. pp. 211-220.

Dorrestijn, E., Mulder, P. (1999) The radical-induced decomposition of 2-methoxyphenol. J. Chem. Soc. Perkin Trans. 2:777-780.

Evans, R.J., Milne, T.A. (1987) Molecular characterization of the pyrolysis of biomass. 2. Applications. Energ. Fuel. 1:311-319.

Evans, R.J., Milne, T.A., Soltys, M.N. (1986) Direct massspectrometric of the pyrolysis of carboneous fuels. III. Primary pyrolysis of lignin. J. Anal. Appl. Pyrol. 9:207-236.

Faix, O., Meier, D., Grobe, I. (1987) Studies on isolated lignins and lignins in woody materials by pyrolysis-gas chromatography- mass spectrometry and off-line pyrolysis-gas chromatography with flame ionization detection. J. Anal. Appl. Pyrol. 11:403-416.

Faix, O., Jakab, E., Till, F., Székely, T. (1988) Study on low mass thermal degradation products of milled wood lignins by thermogravimetry-mass-spectrometry. Wood Sci. Technol. 22: 323-334.

Gardner, D.J., Schultz, T.P., McGinnis, G.D. (1985) The pyrolytic behavior of selected lignin preparations. J. Wood Chem. Technol. 5:85-110.

Genuit, W., Boon, J.J., Faix, O. (1987) Characterization of beech milled wood lignin by pyrolysis-gas chromatographyphotoionization mass spectrometry. Anal. Chem. 59:508-513.

Greenwood, P.F., van Heemst, J.D.H., Guthrie, E.A., Hatcher, P.G. (2002) Laser micropyrolysis GC-MS of lignin. J. Anal. Appl. Pyrol. 62:365-373.

Grønli, M.G., Várhegyi, G., Di Blasi, C. (2002) Thermogravimetric analysis and devolatilization kinetics of wood. Ind. Eng. Chem. Res. 41:4201-4208.

Hosoya, T., Kawamoto, H., Saka, S. (2007) Pyrolysis behaviors of wood and its constituent polymers at gasification temperature. J. Anal. Appl. Pyrol. 78:328-336.

Hosoya, T., Kawamoto, H., Saka, S. (2008a) Pyrolysis gasification reactivities of primary tar and char fractions from cellulose and lignin as studied with a closed ampoule reactor. J. Anal. Appl. Pyrol. 83:71-77.

Hosoya, T., Kawamoto, H., Saka, S. (2008b) Secondary reactions of lignin-derived primary tar components. J. Anal. Appl. Pyrol. 83:78-87.

Hosoya, T., Kawamoto, H., Saka, S. (2009) Role of methoxyl group in char formation from lignin-related compounds. J. Anal. Appl. Pyrol. 84:79-83.

Kawamoto, H., Saka, S. (2007) Role of side-chain hydroxyl groups in pyrolytic reaction of phenolic $\beta$-ether type of lignin dimer. J. Wood Chem. Technol. 27:113-120.

Kawamoto, H., Horigoshi, S., Saka, S. (2006) Pyrolysis reactions of various lignin model dimers. J. Wood Sci. 53:168-174.

Kawamoto, H., Horigoshi, S., Saka, S. (2007) Effects of side-chain hydroxyl groups on pyrolytic $\beta$-ether cleavage of phenolic lignin model dimer. J. Wood Sci. 53:268-271.

Kawamoto, H., Nakamura, T., Saka, S. (2008a) Pyrolytic cleavage mechanisms of lignin-ether linkages: a study on $p$-substituted dimers and trimers. Holzforschung 62:50-56.

Kawamoto, H., Ryoritani, M., Saka, S. (2008b) Different pyrolytic cleavage mechanisms of $\beta$-ether bond depending on the sidechain structure of lignin dimers. J. Anal. Appl. Pyrol. 81:88-94.

Li, J., Li, B. Zhang, X. (2002) Comparative studies of thermal degradation between larch lignin and manchurian ash lignin. Polym. Degrad. Stabil. 78:279-285.

Liu, Q., Wang, S., Zheng, Y., Luo, Z., Cen, K. (2008) Mechanism study of wood lignin pyrolysis by using TG-FTIR analysis. J. Anal. Appl. Pyrol. 82:170-177.

Martin, F., Saiz-Jimenez, C., Gonzalez-Vila, F.J. (1979) Pyrolysis-gaschromatography-mass-spectrometry of lignins. Holzforschung 33:210-212.

Meier, D., Faix, O. (1992) Pyrolysis-gas chromatography-mass spectrometry. In: Methods in Lignin Chemistry. Eds. Lin, S.Y., Dence, C.W. Springer-Verlag, Berlin-Heidelberg. pp. 177-199.

Masuku, C.P. (1991) Thermal reactions of the bonds in lignin IV. Thermolysis of dimethoxyphenols. Holzforschung 45:181-190.

Nakamura, T., Kawamoto, H., Saka, S. (2007) Condensation reactions of some lignin related compounds at relatively low pyrolysis temperature. J. Wood Chem. Technol. 27:121-133. 
Nakamura, T., Kawamoto, H., Saka, S. (2008) Pyrolysis behavior of Japanese cedar wood lignin studied with various model dimers. J. Anal. Appl. Pyrol. 81:173-182.

Obst, J.R. (1983) Analytical pyrolysis of hardwood and softwood lignins and its use in lignin-type determination of hardwood vessel element. J. Wood Chem. Technol. 3:377-397.

Parsons, A.F. (2000) An Introduction to Free Radical Chemistry. Blackwell Science, Oxford. pp. 87-90.

Saiz-Jimenez, C., De Leeuw, J.W. (1986) Lignin pyrolysis products: their structures and their significance as biomarkers. Org. Geochem. 10:869-876.

Schlosberg, R.H., Szajowski, P.F., Dupre, G.D., Danik, J.A., Kurs, A., Ashe, T.R., Olmstead, W.N. (1983) Pyrolysis studies of organic oxygenates: 3 . High temperature rearrangement of aryl alkyl ethers. Fuel 62:690-694.

Scott, D.S., Majerski, P., Piskorz, J., Radlein, D. (1999) A second look at fast pyrolysis of biomass - the RTI process. J. Anal. Appl. Pyrol. 51:23-37.

Shadkami, F., Helleur, R. (2010) Recent applications in analytical thermochemolysis. J. Anal. Appl. Pyrol. 89:2-16.
Vane, C.H., Abbott, G.D. (1999) Proxies for land plant biomass: closed system pyrolysis of some methoxyphenols. Org. Geochem. 30:1535-1541.

Vuori, A. (1986) Pyrolysis studies of some simple coal related aromatic methyl ethers. Fuel 65:1575-1583.

Vuori, A.I., Bredenberg, J.B. (1985) Thermolysis of substituted anisoles. ACS Div. Fuel Chem. 30:366-378.

Vuori, A.I., Bredenberg, J.B. (1987) Thermal chemistry pathways of substituted anisoles. Ind. Eng. Chem. Res. 26:359-365.

Watanabe, T., Kawamoto, H., Saka, S. (2009) Radical chain reactions in pyrolytic cleavage of the linkages of lignin model dimers and a trimer. Holzforschung 63:424-430.

Windt, M., Meier, D., Lehnen, R. (2011) Quantification of polypropylene (PP) in wood plastic composites (WPCs) by analytical pyrolysis (Py) and differential scanning calorimetry (DSC). Holzforschung 65:199-207.

Received March 9, 2011. Accepted October 10, 2011.

Previously published online November 16, 2011. 